\title{
Clinical experience with arthroscopically-assisted repair of peripheral triangular fibrocartilage complex tears in adolescents — technique and results
}

\author{
Christian K. Spies $^{1}$ - Frank Unglaub ${ }^{1,2}$
}

Received: 1 May 2015 / Accepted: 8 May 2015 /Published online: 10 July 2015

(C) SICOT aisbl 2015

To the Editor:

It was with great interest that we read Farr et al.'s article [1] "Clinical experience with arthroscopically-assisted repair of peripheral triangular fibrocartilage complex tears in adolescentstechnique and results.". In this article, the authors examined adolescents who suffered from triangular fibrocartilage complex (TFCC) 1B tears among other pathologies postoperatively after TFCC refixation to the capsule.

TFCC tears and concomitant distal radioulnar joint (DRUJ) instability are often neglected entities among young patients [2]. Therefore, the study is of relevance and the postoperative results are very encouraging.

Nevertheless, in our opinion, several issues ought to be pointed out. Since you examined the DRUJ postoperatively, did you assess the latter prior to surgery? In this context, we often regard the assessment of the DRUJ as a real challenge [3,4]. What test do you apply or prefer for detecting DRUJ instability? It would be interesting to know if patients suffered from DRUJ instability prior to surgery. In cases of DRUJ instability, it may be of relevance if the results of these patients were assessed separately.

Moreover, did the authors find significant differences of sturdiness for the refixation technique applied, since degenerative changes are not to be expected concerning these young patients? We would like to know if the authors regard transosseous refixation as an option for young patients with DRUJ instability?

Christian K. Spies

christianspies27@gmail.com

1 Department of Hand Surgery, Vulpius Klinik, Bad Rappenau, Germany

2 Medical Faculty Mannheim, Ruprecht-Karls-University Heidelberg, Mannheim, Germany
Furthermore, the authors stated that all patients were examined using MRI prior to surgery. We would like to stress that MRI findings should be interpreted very cautiously regarding TFCC lesions, and we agree with the authors that wrist arthroscopy is not only the reference standard for treatment of many wrist pathologies but also for diagnosing [5].

In summary, the study shows clearly that wrist arthroscopy and additional treatment can be performed successfully for young patients.

\section{References}

1. Farr S, Zechmann U, Ganger R, Girsch W (2015) Clinical experience with arthroscopically-assisted repair of peripheral triangular fibrocartilage complex tears in adolescents - technique and results. Int Orthop [Epub ahead of print]

2. Andersson JK, Lindau T, Karlsson J, Fridén J (2014) Distal radioulnar joint instability in children and adolescents after wrist trauma. $\mathrm{J}$ Hand Surg (Eur) 39:653-661

3. Spies CK, Müller LP, Oppermann J, Hahn P, Unglaub F (2014) Instability of the distal radioulnar joint - an overview of clinical and radiological procedures regarding their efficacies. Handchir Mikrochir Plast Chir 46:137-150

4. Hahn P, Wolf MB, Unglaub F (2013) Bilateral test for potential subluxation of the DRUJ. Arch Orthop Trauma Surg 133:1459-1461

5. Löw S, Herold D, Eingartner C (2014) Standard wrist arthroscopy. Technique and documentation. Oper Orthop Traumatol 26:539-546 